\title{
Environmental Management System ISO 14001 factors for promoting the adoption of Cleaner Production practices
}

\author{
José Augusto Oliveira ${ }^{\mathrm{a},{ }^{*}}$, Otávio J. Oliveira ${ }^{\mathrm{b}}$, Aldo R. Ometto ${ }^{\mathrm{c}}$, Antônio S. Ferraudo ${ }^{\mathrm{d}}$, \\ Manoel H. Salgado ${ }^{\mathrm{b}}$ \\ a University of São Paulo (USP), Trabalhador são-carlense Av., 400, São Carlos, 13566-590, São Paulo, Brazil \\ b Production Engineering Department, São Paulo State University (UNESP), Brazil \\ ${ }^{c}$ Production Engineering Department, University of Sao Paulo (USP), Brazil \\ d Department of Mathematical Sciences, Faculty of Agricultural and Veterinary Sciences, São Paulo State University (UNESP), Brazil
}

\section{A R T I C L E I N F O}

\section{Article history:}

Received 7 August 2015

Received in revised form

18 May 2016

Accepted 1 June 2016

Available online 7 June 2016

\section{Keywords:}

Cleaner production

Environmental management system

ISO 14001

Industrial companies

\begin{abstract}
A B S T R A C T
The Environmental Management System of ISO 14001 stands out as one of the most widely used systems for managing corporate environmental aspects and processes and the Cleaner Production is a proactive environmental strategy that has remarkably positive results in environmental corporate management. The principal aim of this article was to identify and analyze the influence relations of the ISO 14001 Environmental Management System to the Cleaner Production through a survey-based research. The maturity and the phases of planning and discipline are key factors for the systematization and continuity of Cleaner Production practices. The stages of Planning, Evaluation and Feasibility Study, and Implementation were identified as the main stages of CP fostered by the ISO 14001 Environmental Management System.
\end{abstract}

() 2016 Elsevier Ltd. All rights reserved.

\section{Introduction}

Corporate Environmental Management has evolved over the years through different stages of development (UNEP, 2007; Dornfeld et al., 2012; Meng et al., 2014). Companies had engaged in a reactive conduct towards environmental issues based on recycling and end-of-pipe treatment practices. Since the 1990s, they started focusing their attention on the root causes of environmental impacts arising from their production processes with a preventive and proactive approach. Afterwards, they have evolved into a stage that is characterized by a broader view and more careful life cycle management of their products and services (UNEP, 2007; Nishitani et al., 2012; Bogue, 2014).

An Environmental Management System (EMS) based on the ISO 14001 standard is aimed at planning a company's operational and administrative activities for managing its environmental aspects and processes (Matthews et al., 2004; Campos, 2012; Oliveira, 2013). In this sense, it sets out requirements for the implementation and management of an EMS (ISO 14001, 2004; Gale, 2005) which can be implemented in companies of any area and size, and

\footnotetext{
* Corresponding author.

E-mail addresses: joseaugusto@sc.usp.br, diogo.apls@gmail.com (J.A. Oliveira).
}

with the most varied stages of development of environmental practices (UNEP, 2007; Meng et al., 2014; Skouloudis et al., 2013). It has a positive and direct influence on business operations (Hunt and Johnson, 1995; Fresner, 1998; Hilson and Nayee, 2002), which leads to an environmental improvement of its processes (Jasch, 2003; Ghisellini and Thurston, 2005; Thoumy and Vachon, 2012).

According to Wu et al. (2008), Pombo and Magrini (2008) and Skouloudis et al. (2013), a significant number of companies worldwide, as well in Brazil (Oliveira et al. (2010) are focused on obtaining an ISO 14001 certification. According to National Institute of Metrology, Standardization and Industrial Quality (INMETRO, 2012), the industrial sector has the largest number of such certificates. Unfortunately, many companies opt for being awarded with an ISO 14001 certification so that it can be used primarily as a marketing tool. Some even believe that it will meet all necessary environmental requirements (Watson and Emery, 2004; Wu et al., 2008; Skouloudis et al., 2013).

On the other hand, the Cleaner Production (CP) stands out as one of the most successful proactive environmental strategies (Özbay and Demirer, 2007; UNEP, 2007; Van Hoof and Lyon, 2013). Furthermore, it leads to competitive advantage gain, corporate image improvement, increased financial returns through modifications in the design of products and processes, reduced material consumption, waste minimization, etc (Shi et al., 2010; Kleměs 
et al., 2012; Scandelari and Cunha, 2013). It should be highlighted, however, that its principal aim is to improve the ecoefficiency of production processes (UNEP, 1995; Baas, 2007; Calia et al., 2009), thus enhancing the environmental performance of organizations effectively (Hicks and Dietmar, 2007; Gianetti et al., 2008; Silva et al., 2013).

Hilson (2003), Khan (2006) and Thoumy and Vachon (2012) state that the $\mathrm{CP}$ is a key factor to increase the environmental management efficacy proposed by the ISO 14001 standard. Several studies suggest that the $\mathrm{CP}$ is an important strategy to maximize the efficiency of human resources (Khan, 2006; Thoumy and Vachon, 2012), the financial resources (Hilson, 2003; Jasch, 2003; Frondel et al., 2007) and the efficacy of the ISO 14001 EMS in companies (Fresner, 1998; Rao and Holt, 2005; Kleměs et al., 2012). However, there are very few studies that examine the influences of the ISO 14001 EMS on the structure and the processes that make up the $\mathrm{CP}$.

Thus, the research questions on which the present study was founded were: are there significant influences of the ISO 14001 EMS on the CP? What are and to what extent do they occur? Hence, the aim of this research was to identify and analyze the influence relations between the ISO14001 EMS and the CP. In order to do so, a survey-based research was conducted with 52 certified Brazilian industrial companies according to the ISO 14001 standard.

After this introduction, the research method is present and the theoretical framework is summarize. After, the results and discussion are shown. Lastly, the conclusion is presented and the references are listed.

\section{Material and methods}

The present work was conducted through a survey-based quantitative research which, according to Jupp (2006) and Cauchick Miguel and Ho (2012), has a descriptive and exploratory character.

Once its theme, research question and objective were selected, a literature review was initiated on the ISO 14001 EMS and CP, which was important for the preparation of the survey questionnaire and data analysis (Forza, 2002; Cauchick Miguel and Ho, 2012), and for discussing the literature review results (Lakatos and Marconi, 1995), thus enabling its conclusions to be drawn.

The questionnaires were sent by e-mail to all 139 Brazilian industrial companies with an ISO 14001 certification, which were found on the database of the INMETRO (2012). In 2012, 52 questionnaires were fully filled in, which represents $37.41 \%$ return. According to Jupp (2006), Forza (2002) and Cauchick Miguel and Ho (2012), this return rate is considered satisfactory and suitable for a survey-based research.

According to Forza (2002) and Synodinos (2003), the sample's choice and the selection of the respondents are fundamental requirements for a survey to be successful. Therefore, it was requested that the questionnaires should have been answered by the Management Representatives (MR) or by managers who were responsible for the ISO 14001 EMSs. They were chosen because they are most likely those who have the greatest knowledge on the characteristics of the EMS and CP, the ISO 14001 standard requirements and general environmental practices of each company.

The questionnaire was divided into four main sections: companies' characterization (SEBRAE, 2015); CP practices (UNEP, 1995); The ISO 14001 EMS's general characterization (ISO 14001, 2004); and evaluation of the influence relations of the ISO 14001 EMS over the CP. The answers were according to the Likert scale, where 5 represents "totally agree" and 1 means "totally disagree".

Before being sent out to companies, the questionnaire was checked by two specialists and two managers in order to verify the relevance and clarity of the questions. Fig. 1 illustrates the present research's methodological sequence.

Initially, the hierarchical cluster analysis method was applied with the purpose of understanding the structure of clusters contained in the original set. The analysis was processed with the Euclidean distance to calculate the similarity between organizations, and the Ward's method was used to merge the clusters (Hair et al., 2009).

Two main processes that were responsible for the main variability of the evaluated variables were identified through the Factor Analysis, which is an exploratory multivariate technique that allows identifying relations between a set of variables to be explained in terms of a limited number of new latent variables. The factors were extracted by the principal component analysis from a correlation matrix between the variables (Hair et al., 2009). The two processes correspond to the Planning and Implementation stages of $\mathrm{CP}$ opportunities, thus the processes were named "Planning, Evaluation and Feasibility Study of the CP" and "Implementation of $C P$ Opportunities", respectively.

The first factor extracted from this matrix is a linear combination of the original variables, which represents the greatest possible variability in the samples. The second factor accounts for the greatest remaining variability, and so forth. The factors are mutually independent and have no units because the variables were standardized. The factors were rotated by the Varimax rotation method. The reliability level of the questionnaire was estimated by Crombach's Alpha coefficient (values between 0 and 1 ), as shown in equation (1):

$\alpha=\frac{k}{k-1}\left[\frac{\sigma_{\tau}^{2}-\sum_{i=1}^{k} \sigma_{i}^{2}}{\sigma_{\tau}^{2}}\right]$

where $\sigma_{i}^{2}$ represents the variance of each question $i(i=1,2, \ldots k)$ and $\sigma_{\tau}^{2}$ is the variance of the sum of the answers of each respondent. The lowest limit for Crombach's Alpha coefficient which is usually accepted is 0.70 , and when it comes to exploratory analyses, 0.60 is acceptable (Hair et al., 2009). The questionnaire had a high Cronbach's Alpha coefficient (0.9296), indicating that the instrument shows a high degree of reliability. All analyses were processed in the Statistica statistical software, version 12.

Some variables were not included in the factor analysis due to being below 0.60 . However, these variables deserve individual analyses and tests because they have supported the hypotheses proposed in this research, and are directly related to some of the variables included in Factors 1 and 2. Consequently, the Kruskal-Wallis test was used, which is a nonparametric method used in a set of samples to test out hypotheses of distribution among populations (Forza, 2002; Hair et al., 2009; Field, 2013).

Forza (2002), Hair et al. (2009) and Field (2013) also added that the Kuskal-Wallis test should be used when the variables have no normality, or when the tested groups do not have the same variability. These test is one of main tests applied to non parametric and/or categorical variables, as pointed by Hair et al. (2009). In this way, the test was conducted considering the mean values (arithmetic means and medians) of specific variables of each block of questions in order to validate the hypotheses formulated for the present research. This test is used considering the Alpha value $(\mathrm{p}=0.05)$ and its results are arranged as follows:

- If $\mathrm{p}>0.05, \mathrm{H} 0$ is accepted and it is assumed that the data come from the same population; and

- If $\mathrm{p}<0.05, \mathrm{H} 0$ is rejected and it is assumed that the data come from at least two different populations. 


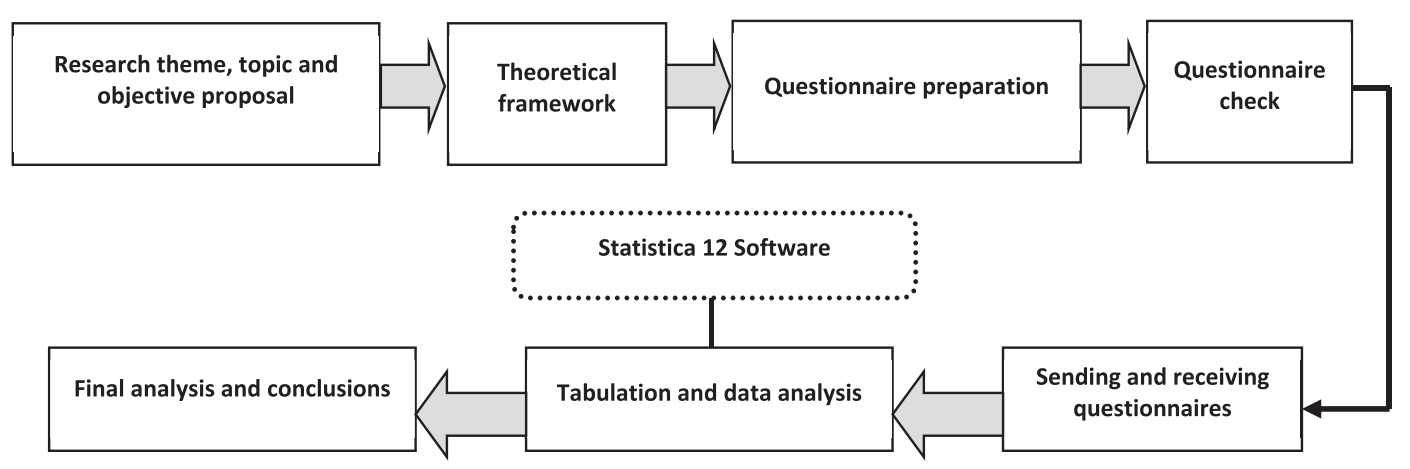

Fig. 1. - Research development methodological sequence.

Equation (2) was obtained from a regression analysis considering the correlation coefficient between the means of the last couple of blocks of the questionnaire:

$\overline{\mathrm{B}}=1,35+0,685 \overline{\mathrm{C}}$

The equation indicates that $\bar{B}$ has a linear relation (statistically significant when $\mathrm{p}=0.000$ ) with $\overline{\mathrm{C}}$, i.e. having information about $\overline{\mathrm{B}}$ can infer and/or estimate scores for $\overline{\mathrm{C}}$. Moreover, as the score of $\overline{\mathrm{B}}$ of a particular organization increases, the score of $\bar{C}$ also tends to increase.

\section{Synthesis of theory}

\subsection{The ISO 14001 Environmental Management System}

Nowadays, most companies implement their EMSs based on the ISO 14001 standard worldwide (Khalili and Duecker, 2013; Skouloudis et al., 2013). These EMS can be used by all of organizations types, sectors and sizes (Stevens et al., 2012; Fields, 2013). It imposes certifiable requirements for the implementation and operation of an EMS in organizations, and is part of the ISO 14000 family which was created in 1996 by the International Organization for Standardization (ISO 14001, 2004; Hilson and Nayee, 2002; Ghisellini and Thurston, 2005).

The ISO 14001 standard does not establish specific performance criteria, nor a maturity model for environmental procedures and control indicators (Watson and Emery, 2004; Ann et al., 2006; Stevens et al., 2012), but it clearly lays down the requirements (environmental policy, planning, implementation, operation, verification, corrective action, and critical analysis by management), that the organization must satisfy in order to be certified (ISO 14001, 2004).

Moreover, it is a major benchmark for companies to operate in an environmentally friendly manner (Saizarbitoria et al., 2006; Oliveira et al., 2010; Skouloudis et al., 2013) due to assisting them in achieving their environmental and economic targets (Ann et al., 2006), thus leading to business sustainability (Watson and Emery, 2004; Avila and Paiva, 2006; Fortunski, 2008).

According to Llomäki and Melanen (2001), Ghisellini and Thurston (2005) and Stevens et al. (2012), despite the growth in the number of ISO 14001 certifications around the world and the benefits reaped by companies that have successfully implemented it, it does not ensure improvements in their environmental performance, because the aim of the EMS depends of each organization and of environmental practices are applied.

The main motivations and benefits for the implementation of an ISO 14001 EMS are (Fryxell and Szeto, 2002; Zeng et al., 2005; Skouloudis et al., 2013):
- Domestic and international market opening;

- Increased consumer satisfaction;

- Compliance with specific environmental legislation of each country;

- Procedure standardization in internal operations;

- Waste reduction and resource conservation in the process (cost reduction);

- Corporate image improvement;

- Environmental awareness increase in the supply chain;

- Clean production procedures establishment;

- Stakeholders expectation fulfillment;

- Environmental performance improvement; and

- Management improvement as a whole.

The main general benefits are commonly provided by this type of system are corporate image improvement, market opening, increased consumer satisfaction, improvement in management systems and increased competitiveness (Berkhout et al., 2001; Fryxell and Szeto, 2002; Sambasivan and Fei, 2008). Moreover, the environmental benefits include the minimization of environmental impacts, increased employee environmental awareness in the supply chain (Field, 2013), and compliance with the local legal environmental requirements (Oliveira et al., 2010; Khalili and Duecker, 2013; Meng et al., 2014).

These benefits have been influencing an increasing number of companies to implement ISO 14001 EMSs (Heras-Saizarbitoria et al., 2011; Skouloudis et al., 2013; Oliveira and Pinheiro, 2009). However, such benefits would actually be obtained if there were top management commitment, preparation, change management, and supervision of external, social and technical aspects (Pojasek, 2003; Sambasivan and Fei, 2008; Stevens et al., 2012). Otherwise, organizations' environmental problems can be covered up, and consequently become more serious (Watson and Emery, 2004; Pojasek, 2008).

According to Ann et al. (2006) and Silva and Medeiros (2004), there are some recurrent difficulties in order to implement an ISO 14001 EMS: the standard's complexity, process documentation strict requirement; low commitment from top management; poor qualification and training; employee resistance; and low financial investment in the system's implementation and maintenance process.

\subsection{Cleaner Production}

The Cleaner Production (CP) is a continuous implementation of an integrated environmental strategy that is aimed at increasing the environmental efficiency of processes, products and services, 
and reducing risks to humans and the environment (UNIDO, 2002; UNIDO, UNEP, 2011).

Once it is implemented, the company operates in a socially (Khan, 2006; Silva Filho et al., 2007) and environmentally friendly manner that brings economic (cost reduction) and technological gains from a preventive and proactive approach which is focused on reducing or eliminating environmental impacts by taking direct action on their root causes, therefore differing from other end-ofpipe strategies (Kleměs et al., 2012; Silva et al., 2013; Yusup et al., 2014).

Essentially, the CP is adopted in companies in two ways:

- Material use minimization through internal recycling or source reduction; and

- Material reuse through external recycling (UNIDO, 2002; CNTL, 2003).

The main factors that might hinder the development of the $\mathrm{CP}$ are: low commitment from top management, environmental issue disregard in corporate strategy, little employee involvement in its project and implementation, search for short-term results, skilled labor shortage, poor training and lack of continuity in activities (Mitchel, 2006; Youngblood et al., 2008; Kleměs et al., 2012).

\subsection{Relation between the ISO 14001 and the Cleaner Production}

CP practices should prioritize the precautionary principle and must be related to one of its three implementation levels: source reduction; internal recycling; and external recycling (Hilson, 2000; Cagno et al., 2005; Frondel et al., 2007). However, the ISO 14001 EMS has a more general approach, and was thought of as to integrate business management as a whole, which includes its integration with the $\mathrm{CP}$.

As there is no specific CP certification which greatly reduces its appeal in marketing terms, it is directly and largely related to corporate interests in preventing and minimizing environmental impacts of production processes (Özbay and Demirer, 2007; Khan, 2006; Zeng et al., 2010).

Companies of any industry, size, location, etc. can use the $\mathrm{CP}$, and it is applicable to any management model due to not having specific content action requirements, but procedural requirements that can be used by organizations of any size, industry, location, among other circumstances (Khan, 2006; Frondel et al., 2007; Kleměs et al., 2012).

Several studies indicate the $\mathrm{CP}$ as an efficient tool for improving the ISO 14001 EMS's performance (Gale, 2005; Frondel et al., 2007; Shi et al., 2010). Fresner (1998), Hilson and Nayee (2002) and Kleměs et al. (2012) affirm that the management and control of environmental impacts proposed by the ISO 14001 can be more easily achieved by systematically following CP practices. Moreover, some benefits that the 14001 EMS is able to bring can be enhanced by CP practices (Robèrt et al., 2002; Hilson and Nayee, 2002; Oliveira et al., 2016).

Companies with greater environmental performance adapt their processes to meet the standard requirements with ease, thus obtaining the ISO 14001 certification more easily, with no need for external consulting (Thoumy and Vachon, 2012; Oliveira et al., 2016), lesser capacity time (Khan, 2006) and lower investment costs for the implementation of the EMS according to the ISO 14001 requirements (Watson and Emery, 2004; Gale, 2005; Pojasek, 2008). Moreover, according to Khan (2006) and Oliveira et al. (2016), these companies are more apt to seek full certification, rather than opt for a partial scope comprising just one sector of the organization.
In this sense, it is observed that the unnecessary external expertise, lower investment costs and shorter time for implementing the EMS according to the ISO 14001 standard requirements, and the option for the full scope of the certification are indicators suggesting a significant maturity of the EMS in companies. Thus, it is expected that companies with an ISO 14001 EMS with higher levels of maturity tend to adopt $\mathrm{CP}$ practices more intensively. Given these observations mentioned in literature, the following hypotheses were formulated for this research:

- H1 - Organizations that have an ISO 14001 certification with full scope tend to adopt CP practices more intensively (Khan, 2006; Kleměs et al., 2012; Yusup et al., 2014);

- H2 - Organizations with no need for an external consultancy service to adapt their process to meet the ISO 14001 requirements tend to adopt $\mathrm{CP}$ practices more intensively (Khan, 2006; Thoumy and Vachon, 2012; Oliveira et al., 2016);

- H3 - Organizations that spend shorter time to adapt their process to meet the ISO 14001 requirements tend to adopt CP practices more intensively (Watson and Emery, 2004 Pojasek, 2008; Oliveira et al., 2016);

- H4 - Organizations that need a minor investment to adapt their process to meet the ISO 14001 requirements tend to adopt CP practices more intensively (Gale, 2005; Pojasek, 2008; Oliveira et al., 2016).

\section{Results and discussion}

The survey sample comprises companies that belong to the industrial sector, with $94 \%$ belonging to the manufacturing industry, $4 \%$ to the extractive industry and $2 \%$ to the construction industry.

Most companies in the sample (69\%) are large. The remainder of the sample is composed of $20 \%$ of mid-sized businesses and $11 \%$ of micro and small businesses. Half these organizations do not export at all, or have less than $25 \%$ of their turnover from exportation. However, the other half derive over $25 \%$ of their turnover from export. Of all companies considered in the sample, $51 \%$ are in the market for over 50 years and $34 \%$ have already been operating from 26 to 50 years' time, and $15 \%$ are in operation for less than 25 years.

Approximately $74 \%$ of the sample defined the total scope for an ISO 14001 certification. In addition, over 84 percent of the studied companies have used the support of consulting firms to implement their ISO 14001 EMS, 14\% have implemented the system in less than 6 months, and the majority (65\%) in up to 12 months. The concept of $\mathrm{CP}$ in this sample is introduced in Fig. 2.

Fig. 2 indicates that $48.08 \%$ of companies fully use the CP. The other level is represented by companies that still use the $\mathrm{CP}$ in an introductory manner (36.54\%). In this way, one can consider that the studied companies have had significant knowledge about $\mathrm{CP}$ practices.

\subsection{Descriptive analyses}

Table 1 presents the questionnaire results, which was aimed at identifying the influence of the ISO 14001 EMS on each level of the $\mathrm{CP}$. Table 1 presents only the answers that resulted in mean values of over 3.5, i.e. representing a score that is above neutrality and around "strong". Mode values that were equal to or less than 3.0 were disregarded in this analysis due to being neutral.

As it can be seen in Table 1, it is possible to consider that the ISO 14001 EMS positively influences the adoption of some basic CP practices. The answers had mean values of over 3.5 and mode values of 4.0, which indicate a "strong" level of agreement among the respondents. 


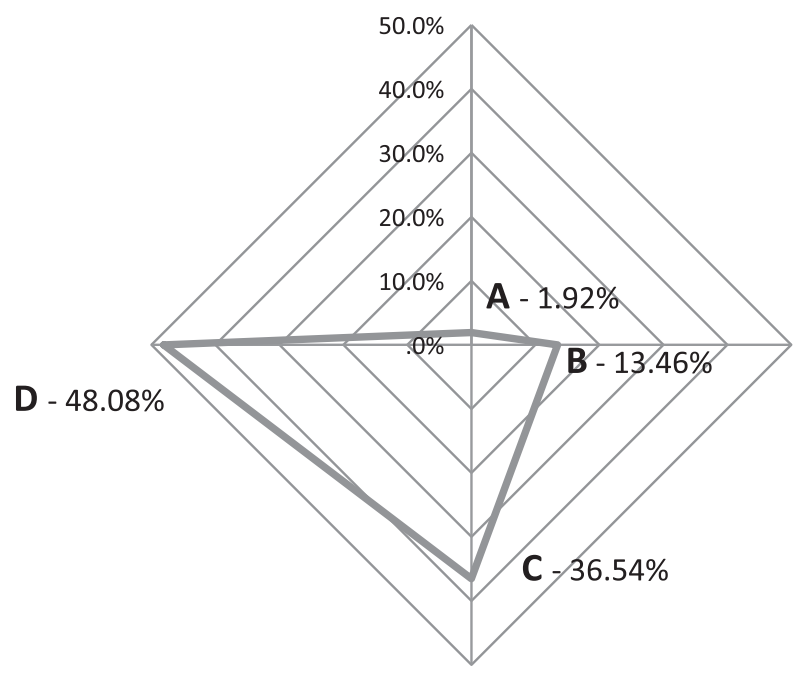

A - 1 the company is unaware

B - 7 companies are aware, but do not use it

C - 19 companies use it, but in an introductory manner

D - 25 companies use it fully

Fig. 2. Knowledge of concept and use of Cleaner Production.

Table 1

Influence relations of the ISO 14001 EMS over the CP.

\begin{tabular}{|c|c|c|c|}
\hline Variable (influence of the ISO 14001 over the CP stages) & Mean & Mode & Standard deviation \\
\hline Top management commitment towards implementing $\mathrm{CP}$ practices & 3.92 & 4 & 0.90 \\
\hline On formulating objectives and targets towards the $\mathrm{CP}$ & 3.96 & 4 & 0.77 \\
\hline On Housekeeping (productive environment) & 3.88 & 4 & 0.70 \\
\hline On systemizing production waste reuse & 3.79 & 4 & 0.78 \\
\hline On monitoring $\mathrm{CP}$ performance & 3.87 & 4 & 0.79 \\
\hline On sustaining these practices (continuous improvement process) & 3.98 & 4 & 0.75 \\
\hline
\end{tabular}

Seeking to understand the logic of these influences, it is worth mentioning that top management attitude towards the environmental issue is vital for the success of an ISO 14001 EMS, and it contributes positively to one of the $\mathrm{CP}$ principles, which is top management commitment and availability to stimulate and contribute with its specific practices.

The ISO 14001 EMS requires the establishment of an environmental policy which must be aligned with the objectives, targets and programs that must go through a continuous and in-depth analysis by the board. In this way, the establishment of goals and objectives towards the $\mathrm{CP}$ is facilitated by the expertise developed in the ISO 14001 planning process.

The systematization of processes and procedures established by the ISO 14001 standard promotes the organization and cleanliness of the workplace. In this sense, housekeeping makes a positive contribution to the productive environment, which is provided by the $\mathrm{CP}$.

The ISO 14001 requires the provision of work instructions, training and control mechanisms for processes that have the most impact on the environment. This feature stimulates the development of measures towards production waste reuse, thus contributing to one of the main levels of the CP.

The ISO 14001 contains specific sections on verification (item 4.5) and critical analysis (item 4.6) of processes that are within the certification scope by the board. These characteristics create favorable conditions to promote $\mathrm{CP}$ practices and assess results continuously.

CP practices sustainability (continuous improvement) can be clearly benefited by the ISO 14001 structure as a whole, which was developed based on the PDCA continuous improvement cycle (plan, do, check and action).

\subsection{Multivariate analysis}

In order to classify these variables into sets of similar organizations, the hierarchical cluster analysis method was applied, which showed that they can be organized into three groups, G1, G2 and G3, as shown in Fig. 3.

G1 comprises medium sized organizations that are in the market for over 30 years. Most organizations (56\%) in this group do not export, and a small portion exports less than $25 \%$ of their turnover. With the exception of organization 33, the group opted for an ISO 14001 certification with full scope. All companies in G1 used external consultancy services for implementing their EMS in order to obtain the ISO 14001 certification within 12 months. In relation to understanding the concept and use of the CP, G1 is characterized, in its majority (84\%), by organizations that use the CP in an introductory and full manner.

All organizations that make up G2 are large and have been operating for over 50 years. Most organizations of this group (55\%) derive from $25 \%$ to $50 \%$ of their turnover from exportation. All opted for a partial certification of their EMSs and have used external consultancy services for its implementation. The implementation/ certification occurred in up to 12 months, given that all these organizations fully utilize use the $\mathrm{CP}$.

G3 is mostly composed of large companies (53\%) that have been operating for less than 50 years, and derive less than $25 \%$ of their turnover from exportation (organizations 1, 4, 7, 8, 10, 16, 17, 23, 30, $31,32,48$ and 52). Most organizations of this group (84\%) opted for an ISO 14001 certification with total scope, and all have used external consultancy services for implementing their EMS. In its majority (58\%), it is characterized by organizations that took up to 12 months to obtain their ISO 14001 certification, but a significant number (26\%) needed 24 months to do so. Three organizations in 


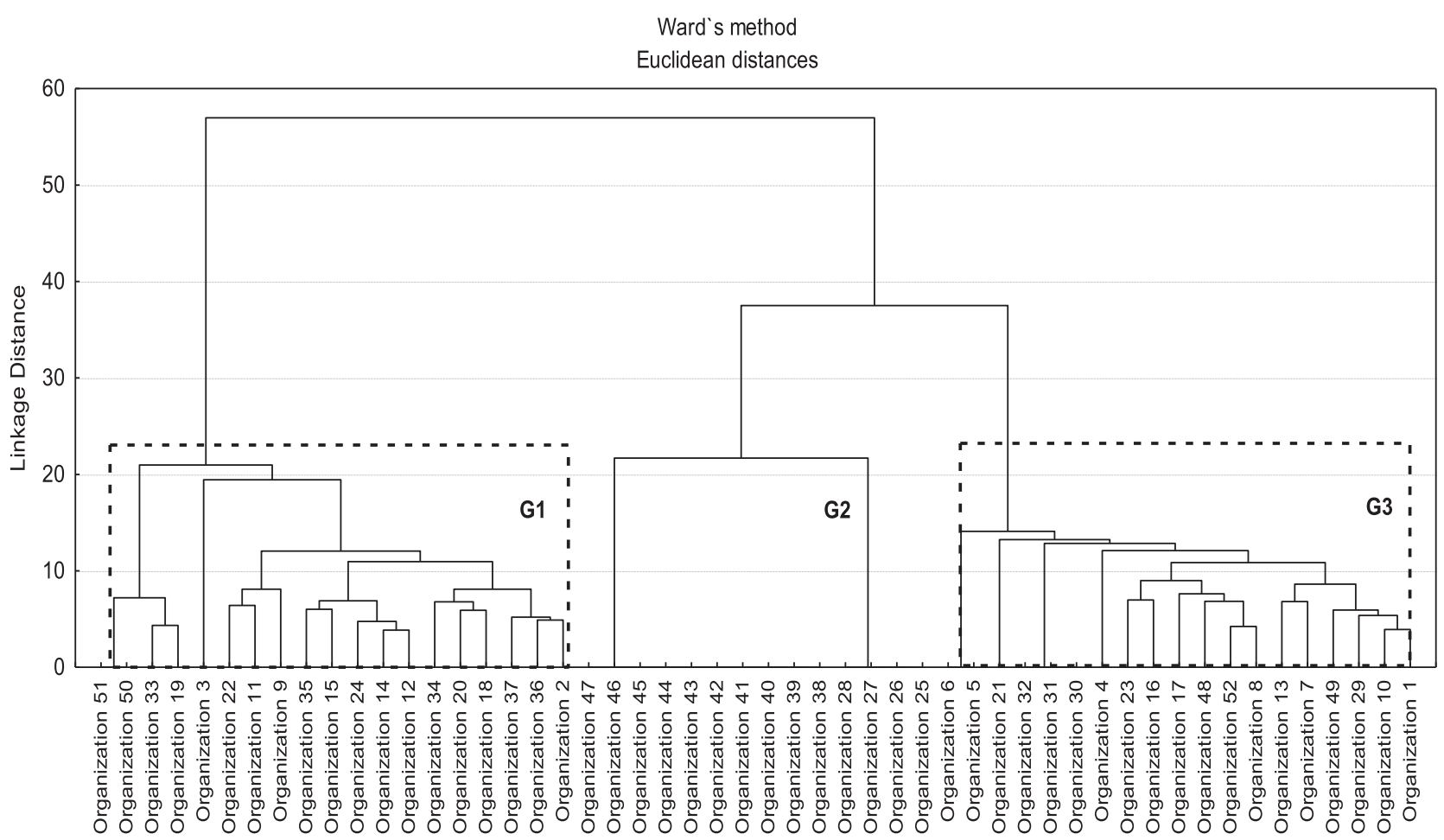

Fig. 3. Dendrogram of the groups' structure through the hierarchical cluster analysis.

G3 (5 percent) took up to 6 months to obtain their ISO 14001 certification, and have fully utilized the CP (Organizations 5, 6 and 29).

Still regarding G3, 58\% took up to 12 months to complete their ISO 14001 certification process, which is composed of organizations that used the $\mathrm{CP}$ in an introductory manner. However, $21 \%$ obtained their certification in up to 24 months or longer (Organizations 10 , 16,17 and 52), which refers to organizations that are either unaware of, or do not use the CP. Fig. 4 presents the centroid containing the mean values of each group.

The values which are close to 1 that are assigned to variable B6 indicate partial ISO 14001 certification scope, and those which are close to 2 indicate total ISO 14001 certification scope. On the other hand, the values which are close to 1 that are assigned to variable B7 indicate the use of external consultancy services for implementing the EMS, and those which are close to 2 represent the nonuse of this type of service.

It is observed in Fig. 4 that the mean curves show similar behavior between variables that characterize the companies and the understanding of the concept and use of the CP. It can be observed that large companies that have been operating for a longer period not only better understand the $\mathrm{CP}$ concept but use it more often. This standard behavior is not observed when analyzing the variable concerning the turnover percentage from exportation (B5). This question, as it is a confidential and strategic corporate
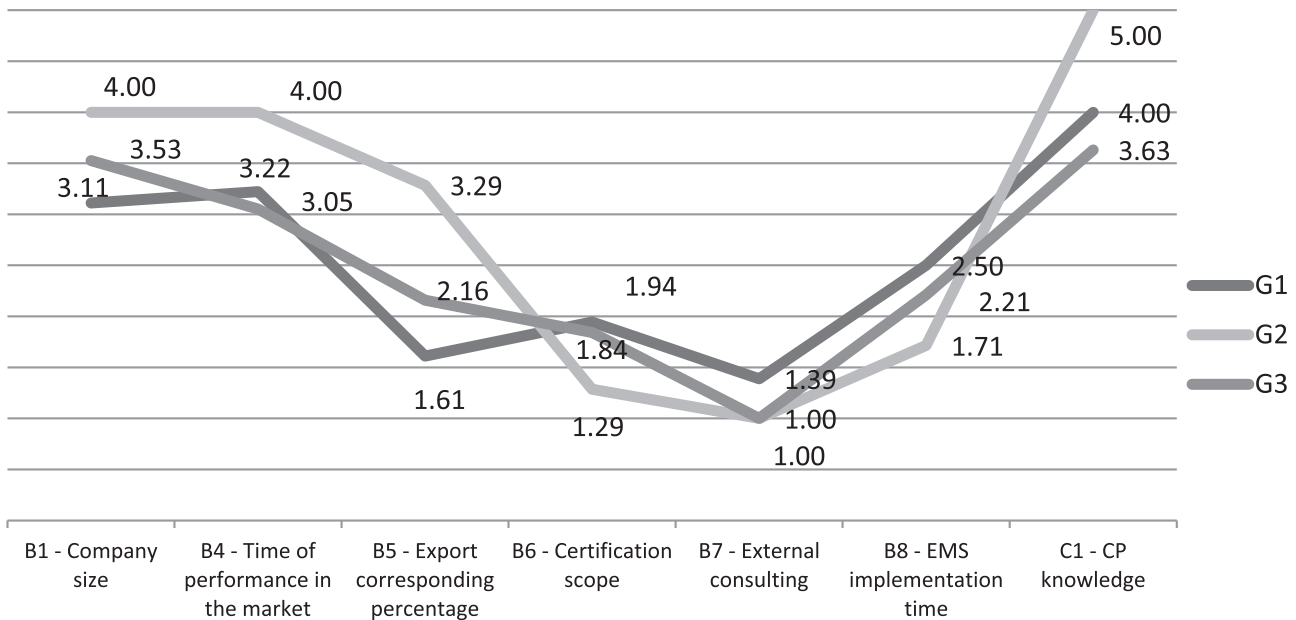

Fig. 4. Mean values of the analyzed variables arranged through the cluster analysis. 
piece of information, might not have been answered with the same level of trust as the other questions, thus it displays distinct behavior outside the curve.

As regards variable B6 (which indicates the EMS's certification scope), it is observed a distinct behavior of G2 in which all companies have opted for partial certification of their EMS, given that in G1 and G2, most companies sought to obtain an EMS certification with total scope. The relation between the time for obtaining an ISO 14001 EMS certification and the understanding and adoption of CP practices is very significant, indicating that companies that took shorter time to obtain it have adopted the $\mathrm{CP}$ practices more seriously, thus constituting a more advanced stage of development in environmental management.

By analyzing the Dendrogram presented in Fig. 3, it was possible to identify the groups' behavior (G1, G2 and G3) of organizations within the total sample of the research. Hence, the tendency of results in different scenarios was assessed.

It was observed a standard behavior of the curve for the three different groups, indicating that the characterization of each of their EMSs is homogeneous. Thus, it is possible to note that the particularities of EMSs in each group are different, but vary in a relatively homogeneous way within the sample. This analysis allows generalizing the EMSs' characterization for the whole research sample, and it also enables their refinement in each group.

Table 2 presents the factor analyses summary which is composed of variables that presented loads equal to or greater than 0.60 .

Two main factors divide the original set of information into two contributing processes of the EMS to the CP. Factors highlighted in Table 2 indicates two sets of variables. Together, they accounted for $66.15 \%$ of the variability contained in the original variables. The variability contained in Factor 1 is $34.73 \%$ and $31.42 \%$ in Factor 2.

Factor 1 shows a positive correlation between a group of variables associated with the stages of "Planning, Evaluation and Feasibility Study of the CP" and, despite the fact that the stage of "Implementation of CP Opportunities" was adopted in the last phase of the $\mathrm{CP}$ process, one can consider it as a planning stage of medium and long-term, as it represents a crucial point for planning future $\mathrm{CP}$ projects from a continuous improvement perspective.

As the loads have the same sign, it is concluded that when one variable increases, the others also increase. Thus, it is observed an increasing and continuous process of contribution and assistance of the EMS, based on the ISO 14001 standard for the CP planning.
This process begins with top management commitment and is followed by the Ecoteam formation, which are essential for establishing and disseminating the planning of the CP program throughout the organization. The policy, objectives, goals, systematization and communication established by the EMS are fundamental in this stage, so that, in conjunction with $\mathrm{CP}$ practices, a process of environmental acculturation is started and disseminated within the company.

This is an important starting point so that the next stages of identifying barriers and opportunities for $\mathrm{CP}$ are made feasible. In a way, this acculturation can contribute to analyses of inputs and outputs of production processes by employees, and towards more in-depth analyses of mass balance, which in turn leads to identifying CP options. Subsequently, the process of technical, economic and environmental assessment of its opportunities begins. The efficiency of this feasibility assessment process can increase by systematizing, communicating and planning the ISO 14001 EMS.

Factor 2 shows a positive correlation between a group of variables associated with the stage of "Implementation of CP opportunities" that were identified, assessed and studied in the previous stages. The management and supervision of environmental aspects and impacts established by the ISO 14001 EMS standard can contribute to the adoption of preventive practices objectified by the $\mathrm{CP}$. As the loads have the same sign and are not inversely proportional, it is concluded that when one variable increases, the others also increase.

The objectives and targets established in the environmental policy of the ISO 14001 EMS standard and assimilated by the Ecoteam and other members of the staff can assist in the stage of Implementation of $C P$ opportunities, once these practices contribute significantly to the prevention and minimization of environmental impacts in the production processes.

\subsection{Hypotheses test}

The four hypotheses put forward in this work were examined by the Kruskal-Wallis test, which are the four important influence relations between the ISO 14001 EMS and the CP identified in the literature review. The Alpha $(\mathrm{p})$ coefficient values are presented in Fig. 5.

For each hypothesis, a null hypothesis and an alternative one were formulated. The hypotheses analysis is as follows:

Table 2

Factor analysis.

\begin{tabular}{|c|c|c|c|c|}
\hline & Variables & Influence of ISO 14001 on the adoption of CP practices & F1 & F2 \\
\hline \multirow[t]{10}{*}{ Planning, Evaluation and Feasibility Study of the CP } & E1 & On top management commitment towards $\mathrm{CP}$ practices & 0.66 & 0.18 \\
\hline & E2 & On assigning the $\mathrm{CP}$ team & 0.74 & 0.37 \\
\hline & $\mathrm{E} 4$ & On identifying $\mathrm{CP}$ barriers & 0.68 & 0.38 \\
\hline & E5 & On preparing the mass balance required for $\mathrm{CP}$ & 0.88 & 0.01 \\
\hline & E6 & On identifying opportunities for $\mathrm{CP}$ implementation & 0.87 & 0.15 \\
\hline & E7 & On the technical assessment of $\mathrm{CP}$ opportunities & 0.91 & 0.20 \\
\hline & E8 & On the economical assessment of $\mathrm{CP}$ opportunities & 0.82 & 0.29 \\
\hline & E9 & On the environmental assessment of $\mathrm{CP}$ opportunities & 0.72 & 0.31 \\
\hline & E10 & On planning the $\mathrm{CP}$ implementation & 0.81 & 0.31 \\
\hline & E19 & On monitoring the performance of selected $\mathrm{CP}$ options & 0.74 & 0.28 \\
\hline \multirow[t]{9}{*}{ Implementation of $\mathrm{CP}$ opportunities } & E11 & On actions to reduce the use of inputs and feedstock at source & 0.23 & 0.83 \\
\hline & E12 & On internal recycling actions in the productive process & 0.15 & 0.87 \\
\hline & E13 & On product modifications for minimizing environmental impacts & 0.30 & 0.84 \\
\hline & E14 & On process modifications for minimizing environmental impacts & 0.19 & 0.91 \\
\hline & E16 & On changing feedstock for minimizing environmental impacts & 0.17 & 0.92 \\
\hline & E17 & On technology modification for minimizing environmental impacts & 0.20 & 0.92 \\
\hline & E18 & On systemizing the reuse of production waste & 0.17 & 0.76 \\
\hline & Expl. Var & & 6.60 & 5.97 \\
\hline & Prp. Totl & & 0.35 & 0.31 \\
\hline
\end{tabular}




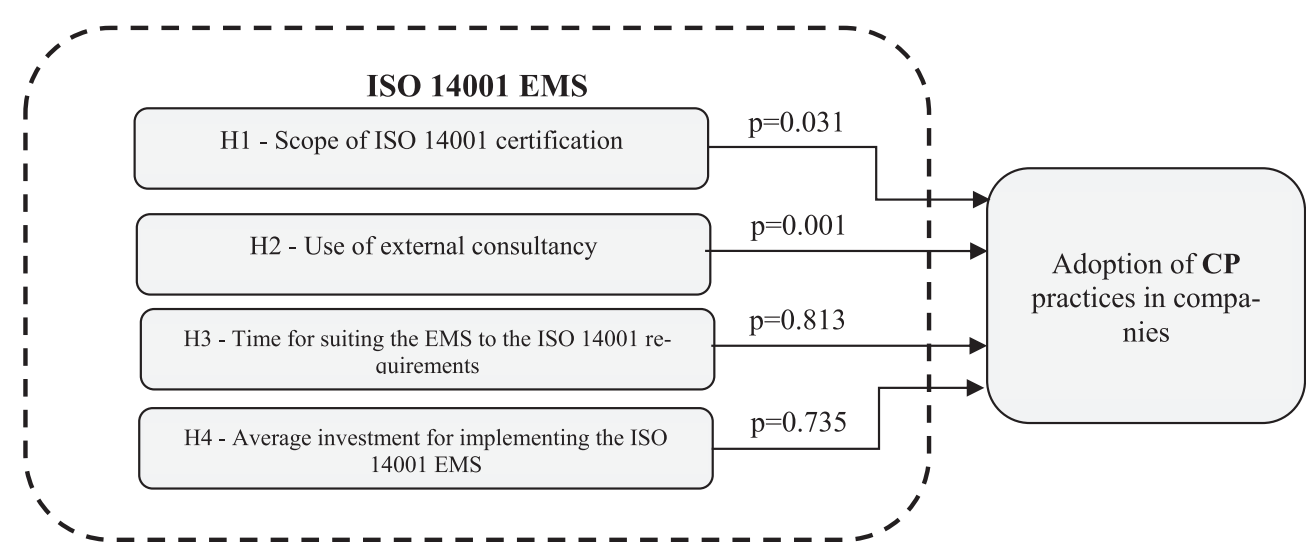

Fig. 5. Research hypotheses test results.

- H1 - Organizations that have an ISO 14001 certification with full scope tend to adopt $\mathrm{CP}$ practices more intensively.

- $\mathrm{H} 1_{\text {(null) }}$ - Companies with a partial certification scope of their ISO 14001 EMS adopt the CP more intensively.

- $\mathrm{H} 1_{\text {(alternative) }}$ - Companies with a total certification scope of their ISO 14001 EMS adopt the CP more intensively.

As $\mathrm{p}<0.05, \mathrm{H} 1_{\text {(null) }}$ is rejected and $\mathrm{H} 1_{\text {(alternative) }}$ is accepted. Thus, it is concluded that opting for an ISO 14001 EMS certification with total scope positively influences the adoption of CP practices. This means that companies that opt for an ISO 14001 EMS certification with total scope have more favorable conditions for the implementation of $\mathrm{CP}$ projects and procedures. In order to hold an ISO 14001 certification with total scope, companies have to foster a more widespread environmental culture, contributing to the identification and implementation of $\mathrm{CP}$ practices in various industries.

- H2 - Organizations with no need for an external consultancy service to adapt their process to meet the ISO 14001 requirements tend to adopt $\mathrm{CP}$ practices more intensively.

- $\mathrm{H} 2$ (null) - The need for external consultancy services for implementing the ISO 14001 EMS is not directly related to the adoption of $\mathrm{CP}$ practices.

- H2 (alternative) - Companies that did not use external consultancy services adopt $\mathrm{CP}$ practices more intensively.

As $\mathrm{p}<0.05, \mathrm{H} 2_{\text {(null) }}$ is rejected and $\mathrm{H} 2_{\text {(alternative) }}$ is accepted. As there was no need for external consultancy services in order to implement their EMS and meet the ISO 14001 requirements, companies have greater awareness and environmental performance, which in turn promotes the implementation and improvement of $\mathrm{CP}$ procedures.

- H3 - Organizations that spend shorter time to adapt their process to meet the ISO 14001 requirements tend to adopt CP practices more intensively.

- H3 (null) - The time required for an ISO 14001 EMS implementation is not directly related to the adoption of $\mathrm{CP}$ practices.

- H3 (alternative) - Companies that require shorter time intervals for implementing an ISO 14001 EMS adopt CP practices more intensively.

As $\mathrm{p}>0.05, \mathrm{H} 3_{\text {(null) }}$ is accepted and $\mathrm{H}_{3}$ (alternative) is rejected. Hence, one can consider that the time spent for implementing an ISO 14001 EMS does not promote the adoption of CP practices. Size, facilities, branches of activity and other features involved with the complexity of processes, products and services of companies can either increase or decrease the time intervals for implementing an ISO 14001 EMS. In this way, this criterion is not exactly a form of promotion for the adoption of CP practices in companies.

- H4 - Organizations that need a minor investment to adapt their process to meet the ISO 14001 requirements tend to adopt CP practices more intensively.

- $\mathrm{H} 4$ (null) - The investment level required to implement an ISO 14001 EMS does not promote CP practices in companies.

- $\mathrm{H} 4$ (alternative) - Companies that require minor investments for implementing an ISO 14001 EMS adopt CP practices more intensively.

As $\mathrm{p}>0.05, \mathrm{H} 4_{\text {(null) }}$ is accepted and $\mathrm{H} 4_{\text {(alternative) }}$ is rejected. It is another criterion that depends on other variables that go beyond the scope of the $\mathrm{CP}$ or of environmental practices adopted by companies. Depending on the business process, the investment for implementing an ISO 14001 EMS is relatively high and it is not directly related to the adoption of $\mathrm{CP}$ practices.

Thus it is concluded that companies with full certification of its EMS and do not need an external consultant to the implementation of this management system adopt more intensely the $\mathrm{CP}$ practices. Notices a promising exploration field for businesses maximize the performance of their EMS with the adoption of CP practices. The planning and correction phases of the EMS exerts a strong influence on the systematic adoption of practices of $\mathrm{CP}$, thus supplying a lack of continuity and systematization of practices occurring in companies that adopt the CP.

While the barriers and conflicts between the requirements of ISO 14001 and the CP practices have not been identified, it is observed although this integrated practice tends to lead to lower costs and investments, since the environmental potential earned by mature EMS favors the practice of $\mathrm{CP}$, which in turn, has significant potential to generate economic returns for companies.

The sample is composed mostly by large enterprises, which corresponds to the majority of Brazilian companies certified by ISO 14001. However, the results could be different if the survey were applied only to medium and small enterprises.

The same can be said if the research was applied to companies' other business sector, as this research has focused on the industrial segment. On the other hand, there is a strong tendency for application of $\mathrm{CP}$ in industry.

In theory, it can be observed that the adoption of $\mathrm{CP}$ practices tends to contribute to the compliance with ISO 14001 requirements and to the implementation and improvement of the EMS as a 
whole, since the $\mathrm{CP}$ promotes significant environmental improvement in the companies' production processes.

In other words, it is expected that companies that practice the $\mathrm{CP}$ more intensely tend to have better conditions and meet ISO 14001 requirements more easily, especially continuous environmental improvement of their processes.

However, the data collection instrument of this research has not been designed to identify how the CP contributes to the SGA and the ISO 14001 requirements, and therefore, it's not possible to conclude anything about this reciprocity between their relationship yet.

\section{Conclusion}

The maturity and the phases of planning and discipline are key factors for the systematization and continuity of CP practices. It was ascertained that there are direct and indirect influence relations between the ISO 14001 EMS requirements and the CP. In two important stages of the $\mathrm{CP}$ (Planning, Evaluation and Feasibility Study of the CP and Implementation of CP opportunities), it was observed a direct contribution of the ISO 14001 EMS, suggesting that compliance with some requirements of the ISO 14001 satisfy a few requirements of the $\mathrm{CP}$. Thus, it is considered that companies with an ISO 14001 EMS certification are in an advantageous position to implement $\mathrm{CP}$ programs and, therefore, to environmentally and proactively manage their business processes.

There is a direct promotion relation of the ISO 14001 EMS in order to go through the ten stages of the $\mathrm{CP}$, which were suggested by its founding agency - UNEP. The hypotheses showed important pieces of information that are directly related to the EMS's performance, therefore to meeting the ISO 14001 requirements. It was found that companies with an ISO 14001 certification with total scope, that did not use external consultancy services for implementing their EMS tended to adopt the CP practices more seriously, showing a greater level of environmental awareness and better conditions for a proactive management of environmental aspects.

It is concluded that an ISO 14001 EMS makes a significant contribution to companies with the adoption of $\mathrm{CP}$ practices because it fosters an environmentally friendly culture within the company and contributes to a systematic allocation of resources for the decision-making processes of directors and managers in this process. On the other hand, this opportunity should be taken by organizations and by the chain in which it operates, considering that the systematization of the practices of $\mathrm{CP}$, even if still in the maturation phase, can be a major advance in the environmental performance of organizations.

Although it has not been directly studied, the inverse relationship that represents the contribution of $\mathrm{CP}$ for the compliance with ISO 14001 requirements and improvement of the EMS can also be observed. This field needs to be empirically explored, but, in theory, it can be observed that companies which practice the $\mathrm{CP}$ have more facilities and conditions to implement the EMS, meet the requirements and achieve ISO 14001 certification.

It is observed that the $\mathrm{CP}$ is adopted by companies with maturity in their EMSs, which indicates that this environmental strategy must be sought by companies looking to continuously improve the environmental performance in front of the requirements of ISO 14001. Going forward, if there is stricter control of environmental aspects ISO 14001, there would be a global trend for anticipating environmental maturity of enterprises and the entire value chain.

The present work fills in a gap identified in literature that rests on a vast field yet to be explored in order to identify, empirically, the various forms of influence relations of the ISO 14001 EMS for implementing the $\mathrm{CP}$, and vice-versa. These relations can be analyzed and applied by the organizations that seek improvements in their EMS and their environmental performance. The relations shown in this paper present a great potential to optimize the ecoefficiency of processes and services, in addition to minimizing costs generated by an isolated management of the EMS and CP.

Both the ISO 14001 standard and the CP keep their structures regardless of the region or country they are inserted in, and the results obtained from this research can be applied to different industries. Thus, they are not only limited to Brazilian enterprises, but can also contribute to corporate management worldwide, since they provide an accurate guide as to adopt practices that aim at meeting the requirements of the ISO 14001 standard, while at the same time adopting environmentally proactive practices according to the precepts of the $\mathrm{CP}$, obtaining better environmental and economic benefits for companies.

The present research limitations are:

- the impossibility to evaluate the conflicting relations of the EMS and the requirements of the ISO 14001 standard for the adoption of CP practices by the data collection instrument used in this research;

- the dependence on the accuracy of information from the answers of each RBD of each company, as it occurs in all types of survey-based researches;

- The data collected refers to a specific time and cannot be said that this research had been carried out prior to last until the present and the future. Note the importance of continuously conducting research like this.

Factors and variables have been identified that can be considered as key for the environmental improvements required by the requirements of ISO 14001. It was not possible to establish a causeeffect relationship, given the limitations of the survey method, so there has been the need for other empirical research methods such as simulations, operations research, action research, etc.

It is suggested for future studies to empirically explore the influence relations that were presented in this work. It is recommended the application of new data collection instruments, focusing on the conflicting relations of the EMS and the requirements of the ISO 14001 standard for the adoption of $\mathrm{CP}$ practices. Finally, this same data collection instrument can be applied in different times, in different countries and in only business sector in order to verify changes in the presented scenario in this work.

\section{Acknowledgements}

The authors would like to gratefully acknowledge the financial aid provided by the Brazilian research funding agencies of $\mathrm{CNPq}$ (National Council for Scientific and Technological Development, through grant no. 479999/2009-0), CAPES (Coordination for higher Education Staff Development) and FAPESP (Sao Paulo Research Foundation).

\section{References}

Ann, G.E., Zailani, S., Wahid, N.A., 2006. A study on the impact of environmental management system (EMS) certification towards firms' performance in Malaysia. Manag. Environ. Qual. Int. J. 17 (1), 73-93.

Avila, G.J., Paiva, E.L., 2006. Processos operacionais e resultados de empresas brasileiras após a certificação ambiental ISO 14001. Revista Gestão Produção, São Carlos 13 (3).

Baas, L., 2007. To make zero emissions technologies and strategies become a reality, the lessons learned of cleaner production dissemination have to be known. J. Clean. Prod 15, 1205-1216. http://dx.doi.org/10.1016/j.jclepro.2006.07.017.

Berkhout, F., Azzone, G., Carlens, J., Hertin, J., Jasch, C.N., 2001. Mepi - Measuring the Environmental Performance of Industry: Final Report. Environment and Climate Research Programme: Research Theme 4-Human Dimensions of 
Environmental Change - contract no. ENV4-CT97-0655. Available in: http:// www/environmental-performance.org. Accessed in 04.01.14.

Bogue, R., 2014. Sustainable manufacturing: a critical discipline for the 21 st century. Assem. Autom. 34 (2).

Cagno, E., Trucco, P., Tardini, L., 2005. Cleaner production and profitability: analysis of 134 industrial pollution prevention (P2) project reports. J. Clean. Prod 13 (6), 593-605. http://dx.doi.org/10.1016/j. jclepro.2003.12.025.

Calia, R.C., Guerrini, F.M., de Castro, M., 2009. The impact of six sigma in the performance of a pollution prevention program. J. Clean. Prod 17, 1303-1310. http://dxdoi:10.1016/j.jclepro.2009.05.001.

Campos, L.M.S., 2012. Environmental management systems (EMS) for small companies: a study in Southern Brazil. J. Clean. Prod. 32, 141-148.

Cauchick Miguel, P.A., Ho, L.L., 2012. Levantamento tipo survey. In: Metodologia de Pesquisa em Engenharia de Produção e Gestão de Operações, second ed. Elsevier, Rio de Janeiro. ABEPRO.

Centro Nacional de Tecnologias Limpas - CNTL. In: Implementação de programas de Produção Mais Limpa, 2003. Apostila, Porto Alegre.

Dornfeld, D., Yuan, C., Dias, N., Zhang, T., Vijayaraghavan, A., 2012. Introduction to green manufacturing. In: Dornfeld, A.D. (Ed.), Green Manufacturing: Fundamentals and Applications. Springer, Berkeley.

Field, A., 2013. Discovering Statistics Using IBM SPSS Statistics. Sage Publications Ltd.

Fortunski, B., 2008. Does the environmental management standard ISO 14001 stimulate sustainable development? Manag. Environ. Qual. Int. J. 19 (2), $204-212$.

Forza, C., 2002. Survey research in operations management: a process-based perspective. Int. J. Oper. Prod. Manag. 22 (2), 152-194.

Fresner, J., 1998. Cleaner production as means for effective environmental management. J. Clean. Prod. 7 (6), 171-179.

Frondel, M., Horbach, J., Rennings, K., 2007. End-of-pipe or cleaner production? an empirical comparison of environmental innovation decisions across OECD countries. Bus. Strategy Environ. 16 (8), 571-584.

Fryxell, G.E., Szeto, A., 2002. The influence of motivations for seeking ISO 14001certification: an empirical study of ISO 14001 certified facilities in Hong Kong. J. Environ. Manag. 65, 223-238.

Gale, R., 2005. Environmental costs at a Canadian paper mill: a case study of Environmental Management Accounting (EMA). J. Clean. Prod. 14 (14), 1237-1251.

Gianetti, B.F., Bonilla, S.H., Silva, I.R., Almeida, C.M.V.B., 2008. Cleaner production practices in a medium size gold-plated jewelry company in Brazil: when little changes make the difference. J. Clean. Prod 16,1106-1117. http://dx.doi:10.1016 j.jclepro.2007.06.002.

Ghisellini, A., Thurston, D.L., 2005. Decision traps in ISO 14001 implementation process: case study results from Illinois certified companies. J. Clean. Prod. 13 (8), 763-777.

Hair, F.J., Black, W.C., Babin, B., Anderson, R.E., Tathan, R.L., 2009. Análise multivariada de dados, sixth ed. Bookman, Porto Alegre.

Heras-Saizarbitoria, I., Landín, G.A., Molina-Azorín, J.F., 2011. Do drivers matter for the benefits of ISO 14001? Int. J. Oper. Prod. Manag. 32 (2), 192-215.

Hicks, C., Dietmar, R., 2007. Improving cleaner production through the application of environmental management tools in China. J. Clean. Prod 15, 395-408. http://dx.doi:10.1016/j.jclepro.2005.11.008.

Hilson, G., 2000. Barriers to implementing cleaner technologies and cleaner production $(\mathrm{CP})$ practices in the mining industry: a case study of the Americas Miner. Eng. 13 (7), 699-717.

Hilson, G., 2003. Defining "cleaner production" and "pollution prevention" in the mining context. Miner. Eng. 16 (4), 305-321.

Hilson, G., Nayee, V., 2002. Environmental management system implementation in the mining industry: a key to achieving cleaner production. Int. J. Miner. Process. 64 (1), 19-41.

Hunt, D., Johnson, C., 1995. Environmental Management Systems: Principles and Practice. McGraw-Hill, London.

INMETRO - Instituto Nacional de Metrologia, Normalização e Qualidade Industrial, 2012. Empresas Certificadas ISO 14001. Disponível em. http://www.inmetro. gov.br. Acesso em 10.03.12.

ISO 14001:2004, 2004. Environmental Management Systems: Requirements with Guidance for Use. International Organization for Standardization, Geneva, Switzerland.

Jasch, C., 2003. The use of environmental management accounting (EMA) for identifying environmental costs. J. Clean. Prod. 11 (6), 667-676.

Jupp, V., 2006. The Sage Dictionary of Social Research Methods. Sage Publications London.

Khalili, N.R., Duecker, S., 2013. Application of multi-criteria decision analysis in design of sustainable environmental management system framework. J. Clean. Prod. 47, 188-198.

Khan, Z., 2006. Cleaner production: an economical option for ISO certification in developing countries. J. Clean. Prod. 16 (1), 22-27.

Kleměs, J.J., Varbanov, P.S., Huising, D., 2012. Recent cleaner production advances in process monitoring and optimisation. J. Clean. Prod. 34, 1-8.

Lakatos, E.M., Marconi, M.A., 1995. Fundamentos de metodologia científica, third ed. Atlas, São Paulo.

Llomäki, M., Melanen, M., 2001. Waste minimization in small and medium-sized enterprises - do environmental management systems help? J. Clean. Prod. 9 (3), 209-217.
Matthews, D.H., Christini, G.C., Hendrickson, C.T., 2004. Five elements for organizational decision-making with an environmental management system. Environ. Sci. Technol. 38 (7), 1927-1932.

Meng, X.H., Zeng, S.X., Shi, J.J., Qi, G.Y., Zhang, Z.B., 2014. The relationship between corporate environmental performance and environmental disclosure: an empirical study in China. J. Environ. Manag. 145, 357-367.

Mitchel, C.L., 2006. Beyond barriers: examining root causes behind commonly cited cleaner production barriers in Vietnam. J. Clean. Prod. 14, 1576-1585.

Nishitani, K., Kaneko, S., Fujii, H., Komastu, S., 2012. Are firms' voluntary environmental management activities beneficial for the environment and business? an empirical study focusing on Japanese manufacturing firms. J. Environ. Manag. $105,121-130$.

Oliveira, O.J., 2013. Guidelines for the integration of certifiable management systems in industrial companies. J. Clean. Prod. 58, 124-133.

Oliveira, O.J., Pinheiro, C.R.M.S., 2009. Best practices for the implantation of ISO 14001 norms: a study of change management in two industrial companies in the Midwest region of the state of São Paulo - Brazil. J. Clean. Prod. 17, 883-885.

Oliveira, O.J., Serra, J.R., Salgado, M.H., 2010. Does ISO 14001 work in Brazil? J. Clean. Prod. 18, 1797-1806.

Oliveira, J.A., Oliveira, O.J., Ometto, A.R., Capparelli, H.F., 2016. Guidelines for the integration of EMS based in ISO 14001 with cleaner production. Prod. J. http://dx.doi.org/10.1590/0103-6513.160214.

Özbay, A., Demirer, G.N., 2007. Cleaner production opportunity assessment for a milk processing facility. J. Environ. Manag. 84, 484-493.

Pojasek, R., 2003. Quality toolbox: developing performance after attaining conformance in your environmental management program. Environ. Qual. Manag. 12 (3), 97-102.

Pojasek, R., 2008. Quality toolbox: framing your lean-to-green effort. Environ. Qual. Manag. 18 (1), 85-93.

Pombo, F.R., Magrini, A., 2008. A Panorama de aplicação da norma ISO 14001 no Brasil. Gestão Produção 15 (1), 1-10.

Rao, P., Holt, D., 2005. Do green supply chains lead to competitiveness and economic performance? Int. J. Oper. Prod. Manag. 25 (9), 898-916.

Robèrt, H.H., Schimidt-Bleek, B., Laerderel, J.A., Basile, G., Jansen, J.L., Kuehr, P.P., Thomas, P.P., Suzuki, M., Hawken, P., Wackernagel, M., 2002. Strategic sustainable development - selection, design and synergies of applied tools. J. Clean. Prod. 10 (3), 197-214.

Saizarbitoria, I.H., Fa, M.C., Viadiu, F.M., 2006. ISO 9000 and ISO 14000 standards: an international diffusion model. Int. J. Oper. Prod. Manag. 26 (2), 141-165.

Sambasivan, M., Fei, N.Y., 2008. Evaluation of critical success factors of implementation of ISO 14001 using analytic hierarchy process (AHP): a case study from Malaysia. J. Clean. Prod. 16 (13), 1424-1433.

Scandelari, V.R.N., Cunha, J.C., 2013. Ambidestralidade e desempenho socioambiental de empresas do setor eletroeletrônico. RAE - Rev. Adm. Empres. 53 (2), 183-198.

SEBRAE - Serviço Brasileiro de Apoio às Micro e Pequenas Empresas, 2015. Business Classification criteria.

Shi, H., Chertow, M., Song, Y., 2010. Developing country experience with ecoindustrial parks: a case study of the Tianjin economic-technological development area in China. J. Clean. Prod. 18 (3), 191-199.

Silva, G.C.S., Medeiros, D.D., 2004. Environmental management in Brazilian companies. Manag. Environ. Qual. Int. J. 15 (4), 380-388.

Silva, D.A.L., Delai, I., Castro, M.A.S., Ometto, A.R., 2013. Quality tools applied to Cleaner Production programs: a first approach toward a new methodology. J. Clean. Prod. 47, 174-187.

Silva Filho, J.C.G., Calábria, F.A., Silva, G.C.S., Medeiros, D.D., 2007. Aplicação da Produção mais Limpa em uma empresa como ferramenta de melhoria contínua. Rev. Produção 17 (1).

Skouloudis, A., Jones, K., Sfakianaki, E., Lazoudi, E., Evangelinos, K., 2013. EMAS statement: benign accountability or wishful thinking? insights from the Greek EMAS registry. J. Environ. Manag. 128, 1043-1049.

Stevens, P.A., Batty, W.J., Longhurst, P.J., Drew, G.H., 2012. A critical review of classification of organisations in relation to the voluntary implementation of environmental management systems. J. Environ. Manag. 113, 206-212.

Synodinos, N.E., 2003. The art of questionnaire construction: some important considerations for manufacturing studies. Integr. Manuf. Syst. 14 (3), 221-237.

Thoumy, M., Vachon, S., 2012. Environmental projects and financial performance: exploring the impact of project characteristics. Int. J. Prod. Econ. 140 (1), 28-34.

UNEP, 1995. Cleaner Production: a Training Resource Package in Industry and Environment. Paris.

UNEP, 2007. Life Cycle Management: a Business Guide to Sustainability.

UNIDO. United Nations Industrial Develepment Organization, 2002. Manual on the Development of Cleaner Production Policies - Approaches and Instruments. Guidelines for National Cleaner Production Centres and Programmes. Unido CP Programme, Viena.

UNIDO, UNEP, 2011. Guidance Manual: How to Establish and Operate Cleaner Production Centers. Vienna.

Van Hoof, B., Lyon, T.P., 2013. Cleaner production in small firms taking part in Mexico's sustainable supplier program. J. Clean. Prod. 41, 270-282.

Watson, M., Emery, A.R.T., 2004. Environmental management and auditing systems: the reality of environmental self-regulation. Manag. Audit. J. 19 (7), 916-928.

Wu, S.J., Melnyk, S.A., Calantone, R.J., 2008. Assessing the core resources in the environmental management system from the resource perspective and the contingency perspective. IEEE Trans. Eng. Manag. 55 (2), 304-315. 
Youngblood, G.J., Dvorak, B.I., Woldt, W.E., Hawkey, S.A., Hygnstrom, J.R., 2008. Quantifying and comparing a P2 program's benefits: pollution prevention technical assistance in Nebraska. J. Clean. Prod. 16, 761-770.

Yusup, M.Z., Mahmood, W.H.W., Salleh, M.R., Muhamad, M.R., 2014. The influence factor for the successful implementation of Cleaner Production: a review. J. Teknol. 67 (1), 89-97.
Zeng, S.X., Tam, C.M., Tam, V.W.Y., Deng, Z.M., 2005. Towards implementation of ISO 14001 environmental management systems in selected industries in China. Clean. Prod. 13 (7), 645-656.

Zeng, S.X., Meng, X.H., Yin, H.T., Tam, C.M., Sun, L., 2010. Impact of cleaner production on business performance. J. Clean. Prod. 18 (10-11), 975-983. 